\title{
Vrancea earthquake early warning system: first tests to add location capabilities
}

\author{
A. Marmureanu - M. Craiu - A. Craiu - C. Neagoe • \\ S. Radulescu - C. Ionescu
}

Received: 27 October 2014 / Accepted: 3 November 2014 / Published online: 29 November 2014

(C) Akadémiai Kiadó 2014

\begin{abstract}
Providing warning notification several seconds before dangerous earthquake waves arrive at a target site reduces the property damages and human casualties. Most earthquake early warning systems (EEWS) developed are either regional ("network based") or on-site ("stand alone") systems. The recent upgrade of the seismic network in Romania with high dynamic range accelerometers allows recording of moderate to large magnitude earthquakes at very close epicentral distances (less than $10-20 \mathrm{~km}$ ). This allows an increase of the warning lead-time (the time difference between the alert notification time and the arrival time of potentially destructive waves at a given target). The seismicity of Romania is significantly affected by earthquakes produced by the Vrancea seismic source with intermediate depth events (three shocks/century with magnitude Mw greater than 7.0). In this paper we present the performance of the seismic network in rapidly locate events occurring in the Vrancea area. Since rapid location of earthquakes is the first step in issuing early warning notifications, by reducing the time of the first valid location will lead to an increase the lead-time interval. Also rapid location of events will allow a future upgrade of EEWS to cover the entire Romanian territory.
\end{abstract}

Keywords Earthquake early warning $\cdot$ Vrancea earthquakes $\cdot$ Seismic network performance

\section{Introduction}

An earthquake early warning system allows to detect an ongoing earthquake in real time and to issue fast notification alerts depending on the potential to cause damage in a target site before the destructive earthquake arrives. All these earthquake early warning systems (EEWS) use rapid telemetric analysis of real-time data from seismic sensors deployed in the epicentral area. In the last decades a lot of work has been carried out in order to implement in real

A. Marmureanu $(\varangle) \cdot$ M. Craiu · A. Craiu $\cdot$ C. Neagoe $\cdot$ S. Radulescu $\cdot$ C. Ionescu

National Institute for Earth Physics, Bucharest, Romania

e-mail: marmura@infp.ro 
time early warning systems. Japan, Taiwan, Mexico and Romania have already operational EEWS (Horiuchi et al. 2005; Wu and Zhao 2006; Nakamura 1984, 1988; Odaka et al. 2003; Espinosa-Aranda et al. 2009; Böse et al. 2007; Mărmureanu 2009; Mărmureanu et al. 2010). EEWS are under testing in other regions of the world such as in Italy, Turkey, California and China (Satriano et al. 2010; Zollo et al. 2006; Alcik et al. 2009; Peng et al. 2011; Allen and Kanamori 2003; Allen et al. 2009). Most EEWS developed so far are either regional ("network based") or on-site (stand alone) systems.

The recent upgrade of the seismic networks in Romania with high dynamic range accelerometers allows recording of moderate to large magnitude earthquakes at very close epicentral distances (less than 10-20 km). This allows an increase of the early warning leadtime (the time difference between the alert notification time and the arrival time of potentially destructive waves at a given target). A "regional" earthquake early warning system uses a dense seismic network that monitors an earthquake prone area. In this approach, methodologies to rapidly compute relevant source parameters are used in order to predict, with an acceptable error, a ground motion intensity measure at a distant site where the target is located.

An "on-site" EEWS is based on a single sensor or an array of sensors deployed at the target site that is to be alerted. In this case different parameters are used to predict the peak ground motion (mainly the $\mathrm{S}$ and surface waves) at the same site.

In the last years National Institute for Earth Physics (NIEP) expanded the seismic network (Fig. 1) up to 102 stations that record velocity and acceleration data in real time. NIEP operates also two seismic arrays. The current density of stations allows rapid detection and location of events, a crucial step in optimize and expand the EEWS functionality to the entire country. In order to have a rapid estimation of earthquake location it is necessary to have a dense distribution of seismic network. Depending on the depth of the earthquake there are needed

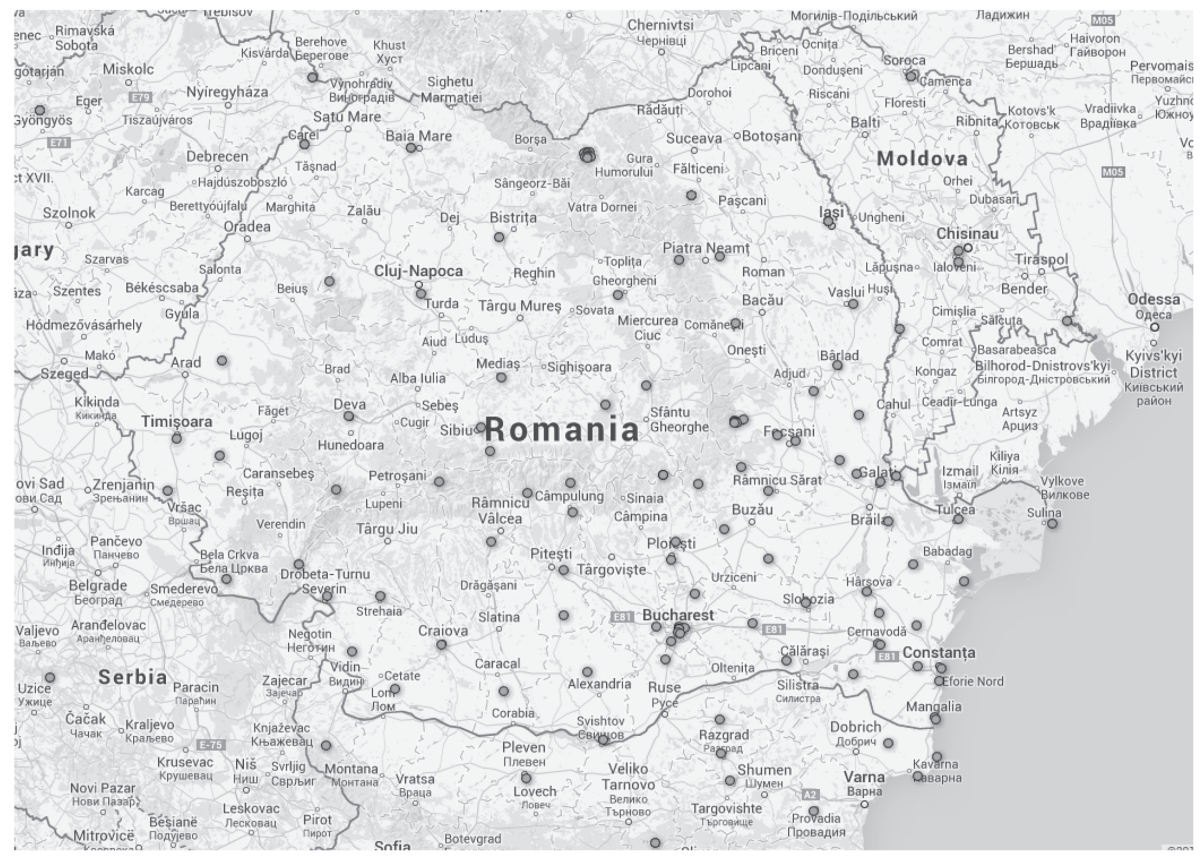

Fig. 1 Romanian Seismic Network (RONET) (August 2014) 


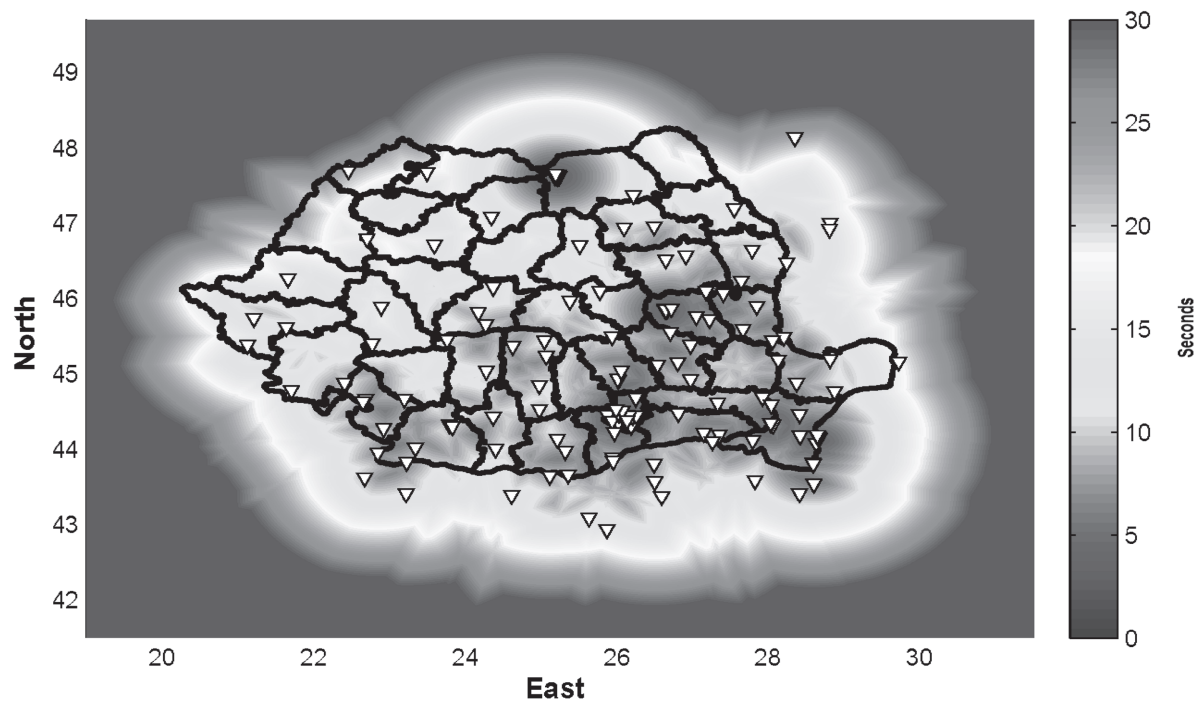

Fig. 2 P wave travel time (seconds) to four stations for a $25 \mathrm{~km}$ depth event

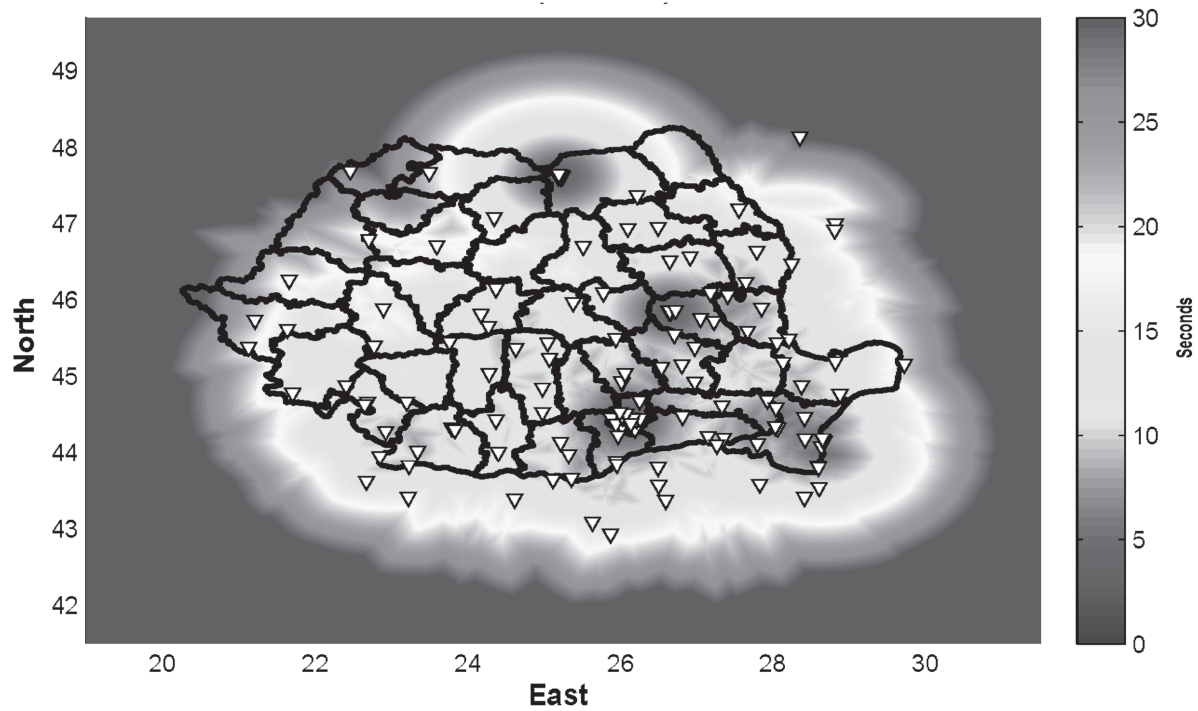

Fig. $3 \mathrm{P}$ wave travel time (seconds) to 6 stations for a $25 \mathrm{~km}$ depth event

four or six P picks associated to an event in order to have a first location of an event. As can be seen from Figs. 2,3,4,5 the Romanian Seismic Network (RONET) geometry allows a theoretical detection of $4 \mathrm{P} / 6 \mathrm{P}$ picks in less than $10 \mathrm{~s}$ for a $25 \mathrm{~km}$ deep events or around 22 $\mathrm{s}$ for a $125 \mathrm{~km}$ deep events. It is also necessary to underline the particular case of Vrancea intermediate depth events and the geometry of the network that allows to have $15 \mathrm{P}$ picks associated for a $125 \mathrm{~km}$ depth event in less than 25 seconds after the origin time (Fig. 6).

The development of an early warning software started at NIEP in 2002. Several versions of real time applications were developed since then. Presently NIEP operates an EEWS that 


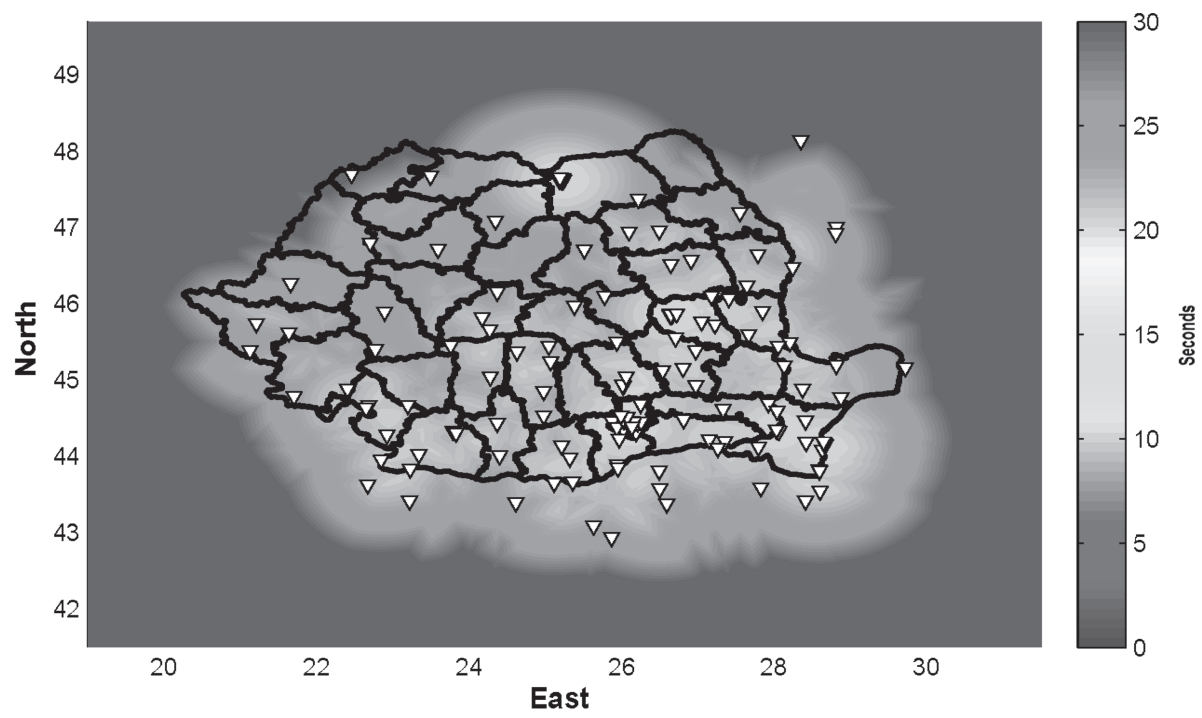

Fig. 4 P wave travel time (seconds) to four stations for a $125 \mathrm{~km}$ depth event

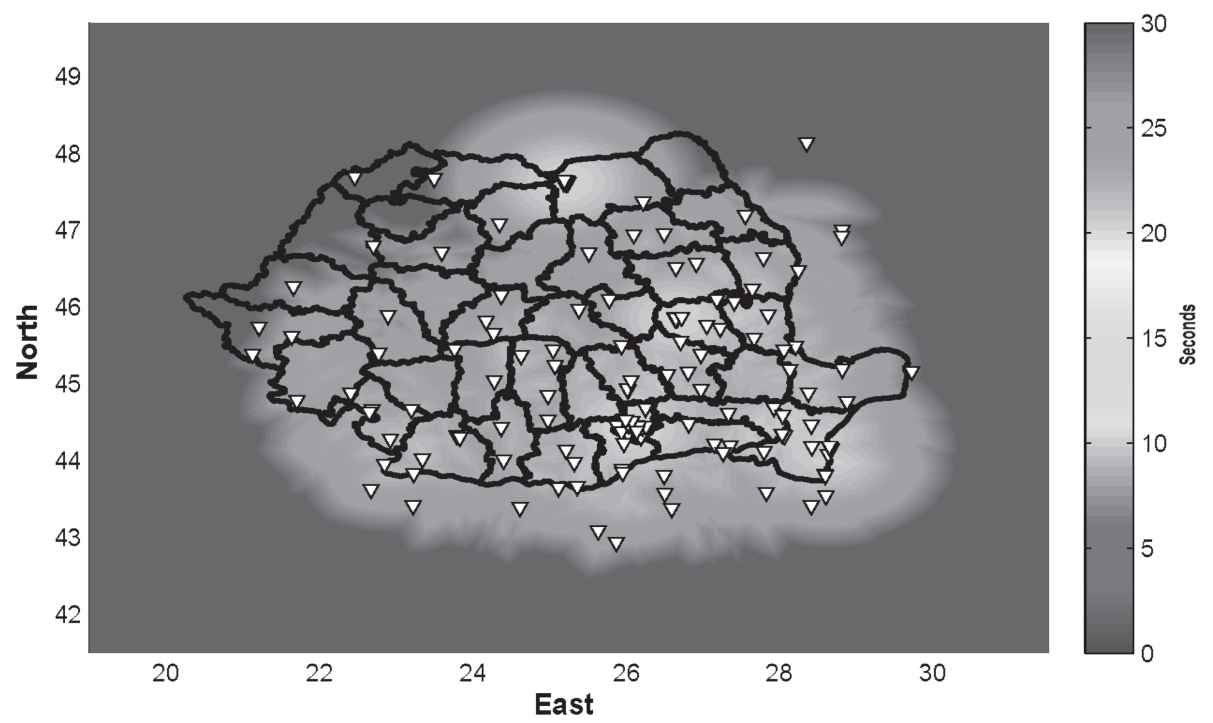

Fig. $5 \mathrm{P}$ wave travel time (seconds) to six stations for a $125 \mathrm{~km}$ depth event

uses only the data from three stations located in the epicentre area. It is designed only for Vrancea intermediate depth events. A set of software modules that share data between them is now implemented in real time around Earthworm acquisition core (Figs. 7 and 8).

At the beginning Kinemetrics K2 digitisers were used at VRI (Vrâncioaia) and PLOR (Ploştina) stations (these stations are located $8 \mathrm{~km}$ one from another). We decided to introduce another Q330 station from MLR (Muntele Roşu). Then we changed Kinemetrics K2s from VRI and PLOR to Quanterra Q330 because it's much faster and stable communication protocol. All these digitizers were able to send data at one second time interval. A third 


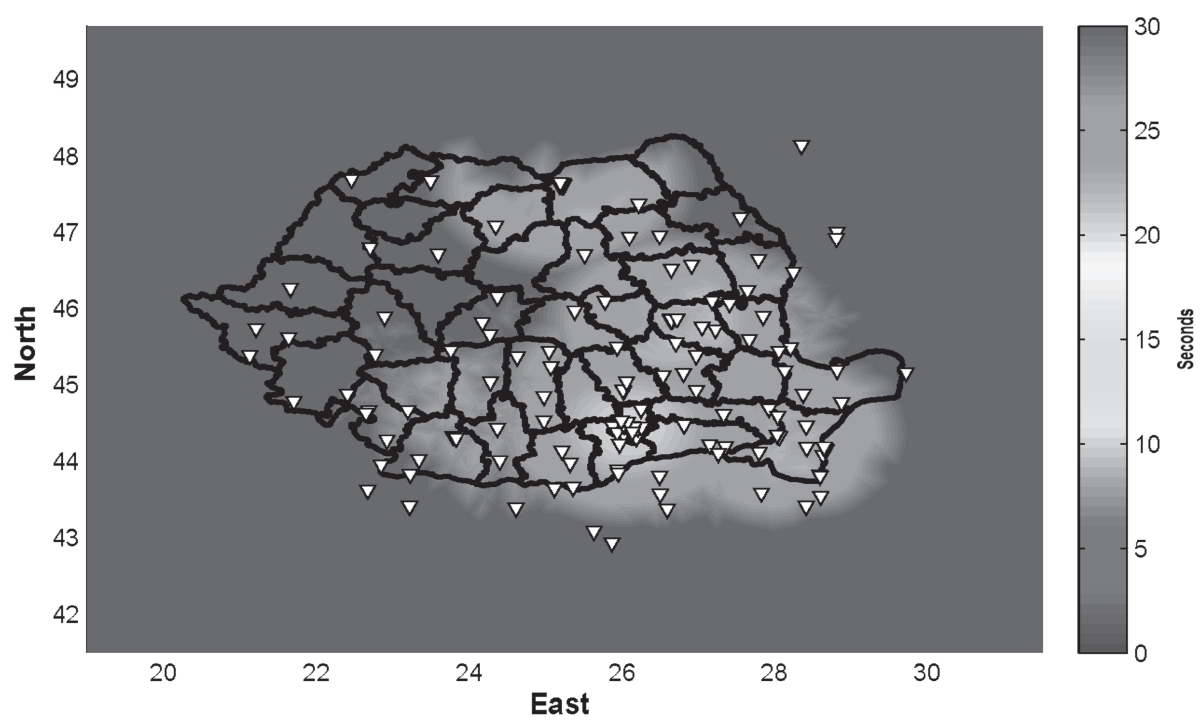

Fig. $6 \mathrm{P}$ wave travel time (seconds) to 15 stations for a $125 \mathrm{~km}$ depth event

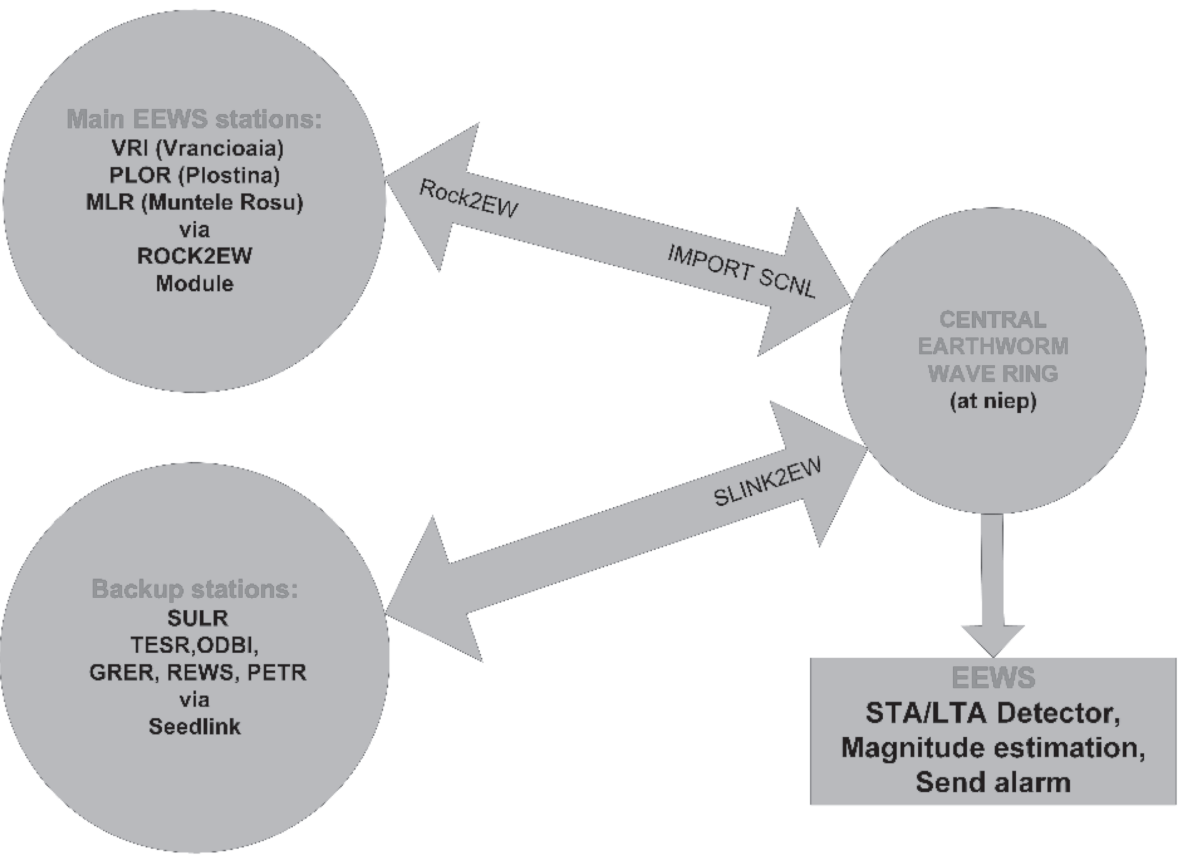

Fig. 7 Real time earthquake early warning system for Vrancea area

update was carried out recently and each of the three above stations use ROCK digitisers that are able to send data as fast as possible (at 1 second interval).

Since the algorithm (Mărmureanu et al. 2010) uses only 3 stations to estimate the magnitude and because it is practically impossible to have them up $100 \%$ of the time, the system 


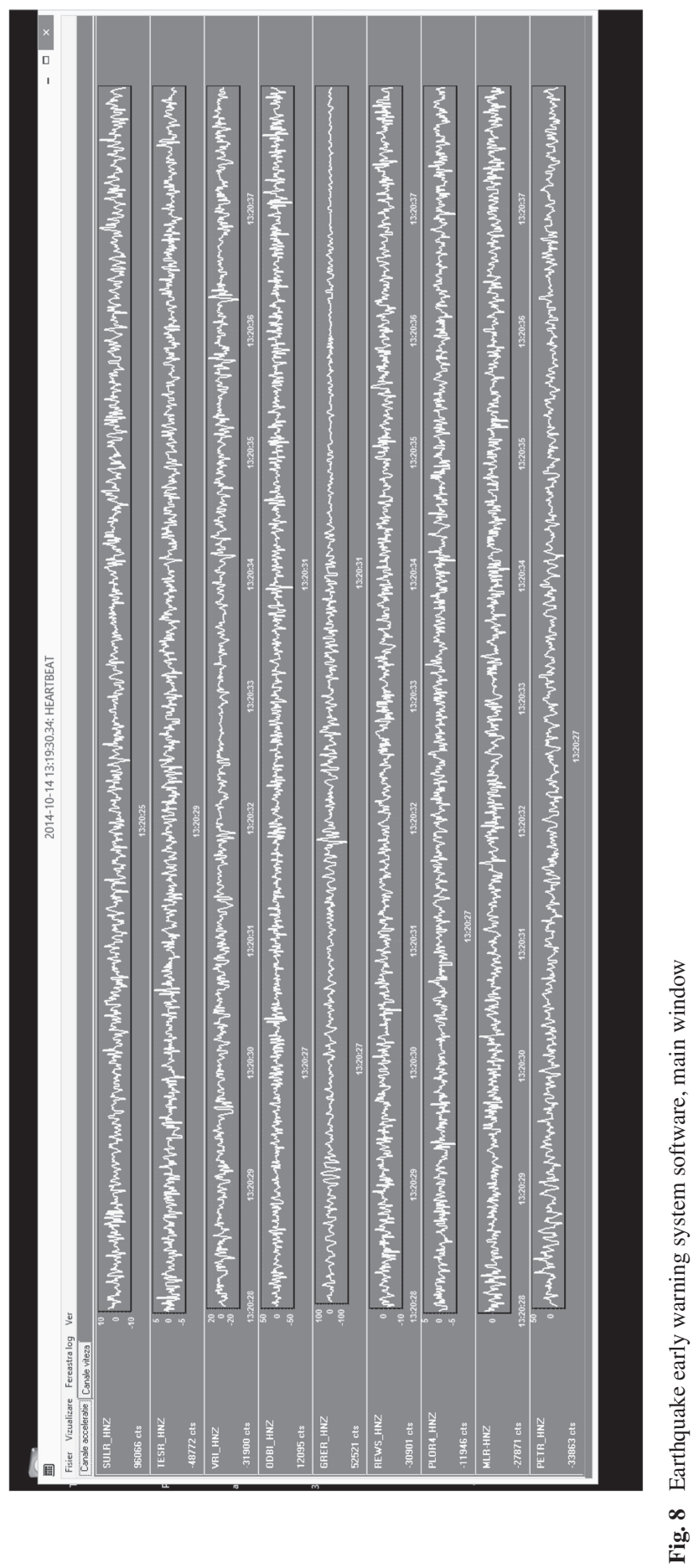




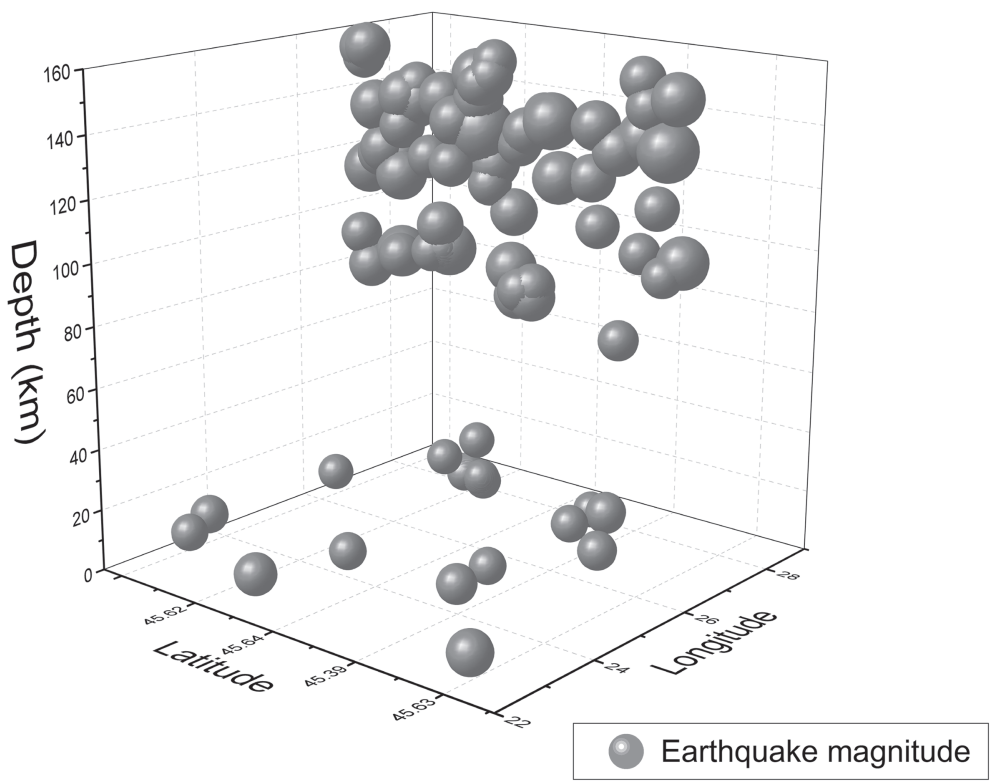

Fig. 9 Location of the events used in the benchmark of location algorithm used

uses other 6 stations as backup, in case one of the main three stations has communication problems. When one of the three stations fails, another station is used from the remaining 6 by considering the best communication available at each site. The software all the time benchmarks the communication with the stations in order to choose the best one in case one of the main fails. The three main stations are preferred because there are installed state of the art equipment that are able to send data continuously at one second time window. All the other stations are streaming data to Bucharest by SeedLink protocol (data packets of 512 bytes that can contain up to 5-6 s). This protocol introduces a latency due to data packing.

EEWS uses the time interval of 25-30 s between the time when the P wave is detected at the surface, in Vrancea epicentral area, and the arrival time of the dangerous $S$ wave at the site that needs to be protected. It uses four modules: (i) The local seismic network for detecting the $\mathrm{P}$ wave, (ii) Two acquisition centres and computing facilities, (iii) a redundant communication network, (iv) a warning distribution network to users.

Since September 2013, there were recorded seven events in Vrancea with magnitude $\mathrm{Mw}>4.0$. All these events were detected by REWS and alerts were sent to:

- S.C.N. Pitesti (A nuclear research facility)

- 16 early warning receivers at the emergency response units located in Bulgaria and Romania: seven in Romania at Constanta, Calaraşi, Giurgiu, Teleorman, Dolj, Olt and Mehedinti and nine receivers in Bulgaria, at: Montana, Vidin, Veliko Tarnovo, Ruse, Belene, Dobrich, Kozlodui, Kozlodui 2 and Silistra.

\section{Methodology and results}

In order to estimate the Romanian Seismic Network (RONET) performance a set of events were used to simulate how fast Seiscomp location procedure performs. For that, a set of events 


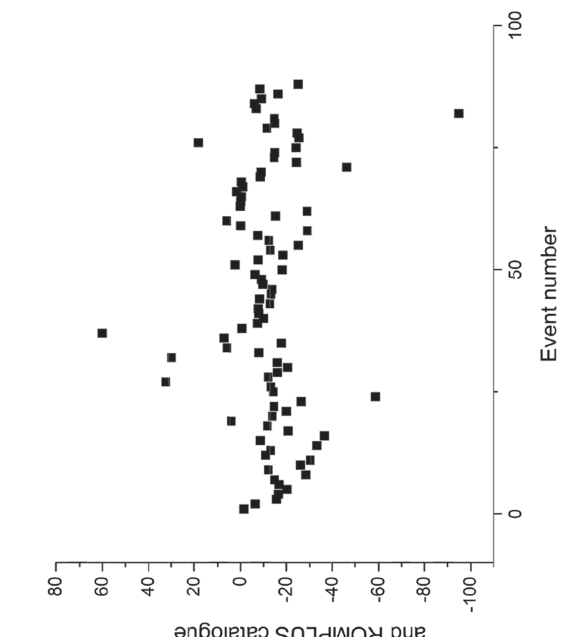

a

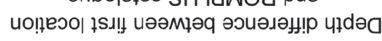
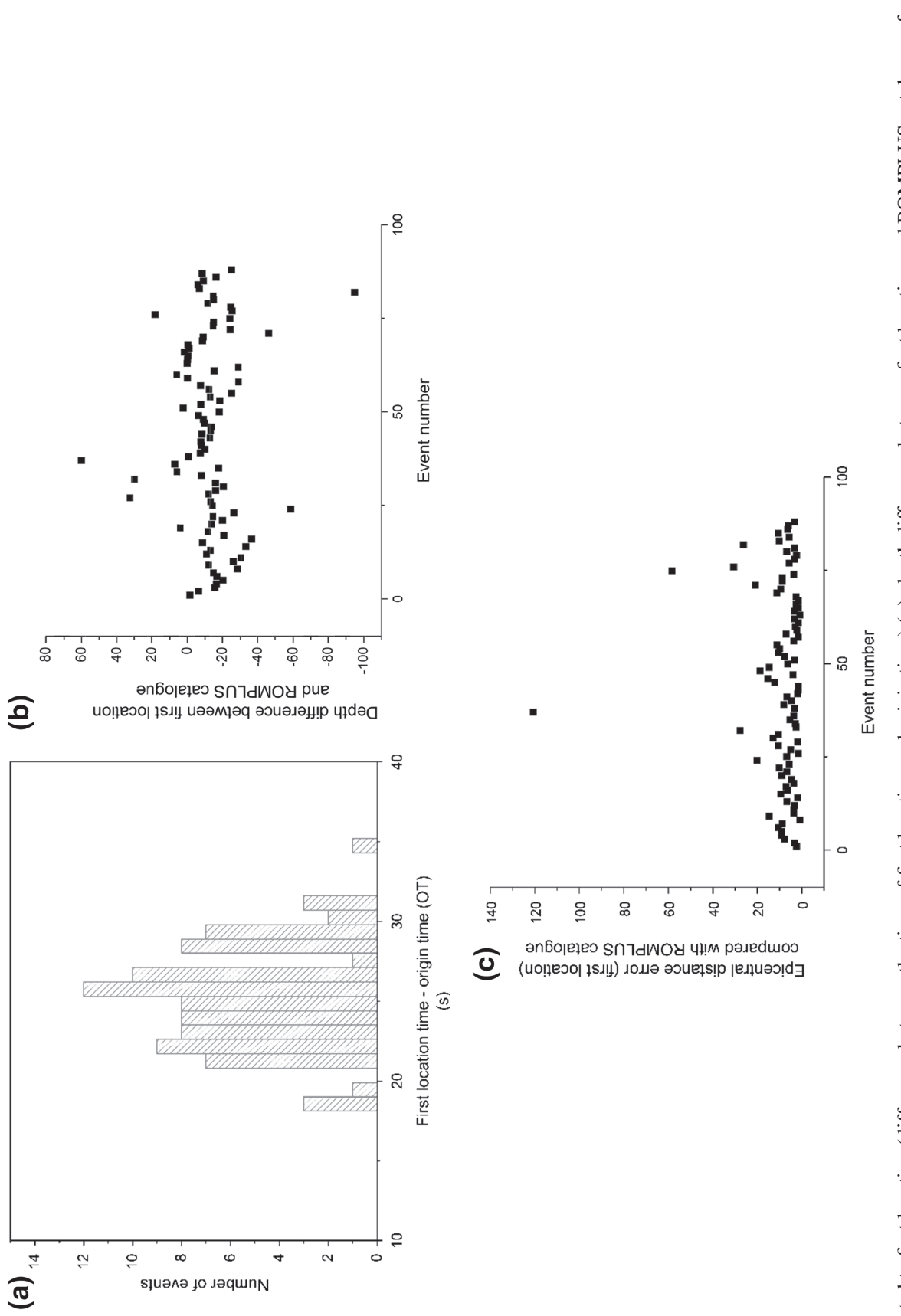
were extracted and offline playback was carried out. The results obtained were compared to the theoretical travel time necessary for the $\mathrm{P}$ waves to reach several stations in order to estimate how fast a first location is produced in real time. A graphical representation of events origin coordinates is plotted in Fig. 9. The majority of selected events originate from Vrancea intermediate depth zone since the seismicity of Romania is significantly affected by earthquakes produced by the Vrancea intermediate depth earthquakes.

For testing the performance of the real-time location inside the RONET the SeisComP3 was used, a seismological software for data acquisition, processing, distribution and interactive analysis that was developed by the GEOFON Program at GFZ, German Research Centre for Geosciences.

The procedure used to identify and locate seismic events has several steps that were optimised in order to get as fast as possible the first location estimation:

(a) $P$ wave detection In this stage a robust STA/LTA picking algorithm was applied on waveform streams. The STA/LTA detector was used after the waveforms were filtered before with a Butterworth filter of third order with corner frequencies of 0.7 and $2 \mathrm{~Hz}$. When a threshold STA/LTA ratio is reached a pick is associated to the time when the threshold is exceeded. We used the STA/LTA threshold value 3.

(b) Location of the seismic event For locating events the scautoloc module was used, a program part of SeisComP responsible for locating seismic events in real-time. Scautoloc automatically processes picks and amplitudes associated to detected picks. The procedure used by scautoloc to identify and locate seismic events consists of following steps: (i) pick preparation — each incoming pick needs to be associated to a specific set of amplitudes; (ii) filtering of peaks-it is checked whether the picks are outdated and if a complete set of amplitudes associated are present; (iii) association-attempt to associate incoming picks with known origins; (iv) nucleation - scautoloc tries to make a new origin with the new picks and other unassociated previously recorded picks (procedure called "nucleation"). In this phase a grid search over time and space is carried out. The grid represents a discrete set of points that sample the area of interest with sufficient resolution. In the grid search, each point of the grid is considered as a possible hypocentre for all received picks. This process require a lot of resources in terms of memory and computational power, especially for Vrancea intermediate depth events that require a deep grid. If the grid is very dense, the resulting location can be used directly; (v) refinement of origin - origins are checked once more for contamination from wrongly interpreted $\mathrm{P}$ picks by using pick signal to noise ratio and amplitude. By removing such "spurious" picks the origin location error is reduced.

By simulation of existing events was found out that the first location of earthquakes is produced very fast. Depending on the depth of the events the first location is produced in most of the cases after $25 \mathrm{~s}$ after origin time (Fig. 10).

\section{Conclusions}

Since September 2013, there were recorded seven events in Vrancea with magnitude Ml > 4.0. All these events were detected by EEWS and alerts were sent to: 16 early warning receivers at the emergency response units located in Bulgaria and Romania: seven in Romania at Constanta, Calaraşi, Giurgiu, Teleorman, Dolj, Olt and Mehedinti and nine receivers in Bulgaria, at: Montana, Vidin, Veliko Tarnovo, Ruse, Belene, Dobrich Kozlodui, Kozlodui 2 and Silistra. 
The present study shows that the existing EEWS can be upgraded to locate in real time the event source since the offline tests show that a stable solution is generally reached within $25 \mathrm{~s}$ from the origin time, depending on the depth of the earthquakes for Vrancea seismic source.

Since rapid location of earthquakes is the first step in issuing early warning notifications, by reducing the time of the first valid location will lead to an increase the lead-time interval. Also rapid location of events will allow a future upgrade of EEWS to cover the entire Romanian territory.

Acknowledgments This work was supported by a grant of the Romanian National Authority for Scientific Research, CNCS-UEFISCDI, project number PN-II-RU-TE-2012-3-0215.

\section{References}

Alcik H, Ozel O, Apaydın N, Erdik M (2009) A study on warning algorithms for Istanbul earthquake early warning system. Geophys Res Lett 36:L00B05

Allen RM, Kanamori H (2003) The potential for earthquake early warning in southern California. Science 300:685-848

Allen RM, Brown H, Hellweg M, Khainovski O, Lombard P, Neuhauser D (2009) Real-time earthquake detection and hazard assessment by ElarmS across California. Geophys Res Lett 36:L00B08. doi:10. 1029/2008GL036766

Böse M, Lonescu C, Wenzel F (2007) Earthquake early warning for Bucharest, Romania: novel and revised scaling relations. Geophys Res Lett 34:1-6

Espinosa-Aranda JM, Cuellar A, Garcia A, Ibarrola G, Islas R, Maldonado S, Rodriguez FH (2009) Evolution of the Mexican Seismic Alert System (SASMEX). Seismol Res Lett 80:694-706

Horiuchi S, Negishi H, Abe K, Kamimura A, Fujinawa Y (2005) An automatic processing system for broadcasting system earthquake alarms. Bull Sesim Soc Am 95:347-353

Mărmureanu A (2009) Rapid magnitude determination for Vrancea early warning system. Rom J Phys 54(910):2009

Mărmureanu A, Ionescu C, Cioflan CO (2010) Advanced real-time acquisition of the Vrancea earthquake early warning system. Soil Dyn Earthq Eng. doi:10.1016/j.soildyn.2010.10.002

Nakamura Y (1984) Development of earthquake early-warning system for the Shinkansen, some recent earthquake engineering research and practical in Japan. In: The Japanese national committee of the international association for earthquake engineering, pp 224-238

Nakamura Y (1988) On the urgent earthquake detection and alarm system (UrEDAS). In: Proceedings 9th world conference earthquake engineering, vol 7, pp 673-678

Odaka T, Ashiya K, Tsukada S, Sato S, Ohtake K, Nozaka D (2003) A new method of quickly estimating epicentral distance and magnitude from a single seismic record. Bull Seismol Soc Am 93:526-532

Peng H, Wu Z, Wu YM, Yu S, Zhang D, Huang W (2011) Developing a prototype earthquake early warning system in the Beijing Capital Region. Seismol Res Lett 82:394-403

Satriano C, Elia L, Martino C, Lancieri M, Zollo A, Iannaccone G (2010) PRESTo, the earthquake early warning system for Southern Italy: concepts, capabilities and future perspectives. Soil Dyn Earthquake Eng. doi:10.1016/j.soildyn.2010.06.008

Wu YM, Zhao L (2006) Magnitude estimation using the first three seconds P-wave amplitude in earthquake early warning. Geophys Res Lett 33:L16312. doi:10.1029/2006GL026871

Zollo A, Lancieri M, Nielsen S (2006) Earthquake magnitude estimation from peak amplitudes of very early seismic signals on strong motion records. Geophys Res Lett 33:L23312. doi:10.1029/2006GL027795 